Рязанский Государственного университета им. С. Есенина, 2. Рязань, Российская Федерация

В.В. Блудов

Байкальский государственный университет, г. Иркутск, Российская Федерация

О.Ю. Оношко

Байкальский государственный университет,

г. Иркутск, Российская Федерация

\author{
ИНФОРМАЛЬНОЕ ОБРАЗОВАНИЕ В ПРОЦЕССЕ ИЗУЧЕНИЯ \\ ИНОСТРАННЫХ ЯЗЫКОВ И ТИПЫ ЗАДАНИЙ, НАЦЕЛИВАЮЩИХ \\ СТУДЕНТОВ НА САМОСТОЯТЕЛЬНУЮ РАБОТУ В УСЛОВИЯХ \\ ИНФОРМАЛЬНОГО ОБРАЗОВАНИЯ
}

\begin{abstract}
АНнотАцИЯ. В статье отражена специфика организации информального образования при обучении студентов в языковом вузе и магистрантов - в экономическом вузе, обучающихся по международным программам, а также значимость осознанной самостоятельной работы и самообразования как неотъемлемого компонента функционирования информального образования. Важной составляющей также является мотивация обучающихся и их методическая подготовленность к самостоятельному изучению иностранного языка. Авторы предлагают для рассмотрения три вида нацеливания обучающихся в процессе формального учебного процесса на самообучение в условиях информального контекста и приводят типологию заданий, иллюстрирующих открытое, косвенное и скрытое нацеливание обучающихся на их самостоятельную работу.

кЛючЕВЫЕ словА. Информальное образование, самообучение, самостоятельная работа, языковое образование, международные образовательные программы вузов. ИНФОРМАЦИЯ О СТАТЬЕ. Дата поступления 15 апреля 2019 г.; дата принятия к печати 21 июня 2019 г.; дата он-лайн-размещения 15 июля 2019 г.
\end{abstract}

T.V. Liskina

S.A. Yesenin Ryazan State University, Ryazan, Russian Federation

V.V. Bludov

Baikal State University, Irkutsk, Russian Federation

O.Yu. Onoshko Baikal State University, Irkutsk, Russian Federation

\title{
INFORMAL EDUCATION IN PROCESS OF STUDYING FOREIGN LANGUAGES AND TYPES OF TASKS THAT AIM STUDENTS AT WORKING INDEPENDENTLY IN TERMS OF INFORMAL EDUCATION
}

ABSTRACT. The article reflects the specificity of organizing informal education in training students in a language university and master degree students in an economic university, enrolled in international programs, as well as the significance of conscious independent work and self-education as an integral component of informal education functioning. An important component is students' motivation and their methodological readiness for independent learning a foreign language. The authors offer for consideration three types of students' guiding to self-learning in terms of

\section{Baikal Research Journal}

электронный научный журнал Байкальского государственного университета 
informal context in the process of formal educational process and provide a typology of tasks illustrating the direct, indirect and hidden guiding of students to their independent work.

KEYWORDS. Informal education, self-education, independent work, self-teaching, language education, international educational programs for universities.

ARTICLE INFO. Received April 15, 2019; accepted June 21, 2019; available online July $15,2019$.

Информальное образование представляет собой «индивидуальную познавательную деятельность человека, осуществляемую ежедневно, которая может иметь как нецеленаправленный характер, так и представлять собой целенаправленную познавательную самостоятельную деятельность в повседневной жизни», включающую осознанную постановку целей, выбор действий, источников и оценку результатов [1, с. 21]. Оно возникает там, где один человек участвует в общении с другими, фокусирует свое внимание на других, и подвергается их учебному и воспитательному воздействию [2]. Необходимость применения данного вида образования при овладении иностранными языками (ИЯ) обусловлена спецификой самого учебного предмета: ведь чтобы успешно и результативно овладеть языком, необходимо систематически «включать»его в повседневную коммуникативную, познавательную и трудовую деятельность, «жить, работать и отдыхать в этом языке». Особое значение информальное образование в области изучения ИЯ приобретает для реализации вузами международных программ. "Расширение международных контактов вузов ставит перед ... вузами задачу не только научить студентов иностранному языку, как неотъемлемому атрибуту культурного развития человека, но и как одному из главных условий его успешной деятельности в самых разных сферах производства» [3, с. 729].

Активное внедрение в практику российских вузов международных образовательных программ и «...политика интеграции России в международное сообщество ставит перед российскими специалистами важную задачу - совершенствовать свои знания в области иностранных языков»[4, с. 150]. В этих целях информальное образование приобретает особую значимость, «... очень активно исследуется педагогическим сообществом и рассматривается с разных точек зрения - философской, лингвистической, педагогической и даже экономической... как инструмент совершенствования человеческого капитала» [5, с. 134].

Потребность в самообразовании и самообучении иностранному языку закладывается и развивается у студентов преимущественно во время обучения в вузе. «Самообразовательная деятельность личности в этот период является предметом изучения большого количества исследователей (А.Я. Айзенберг, Е.Л. Белкин, А.К. Громцева, П.И. Пидкасистый, А.Е. Пискунов, Б.Ф. Райский, Н.А. Рубакин, Г.К. Сериков) и представляет собой неотъемлемый компонент вузовского образования, в основе которого лежат взаимосвязанные процессы самообучения и самовоспитания. Эти взаимоотношения могут переноситься и на уровень языкового образования» [6, с. 77].

В процессе разговоров с активными студентами, заинтересованными преподавателями и людьми, которые просто по собственному желанию ежедневно изучают язык, узнают новые тенденции в языке, используют его в качестве средства обучения, стараются открыть для себя другие возможности и перспективы для изучения языка, становится понятно, что если есть качество, которое проявляется в стремлении к изучению иностранного языка, то оно проявляется и в повседневной жизни. Этот постулат становится особо актуальным, поскольку «ограниченные возможности студентов при общении с носителями иностранного языка и преобладание тренировочной коммуникации со сверстниками и преподавателями,

\section{Baikal Research Journal}

электронный научный журнал Байкальского государственного университета 
которые не всегда имеют опыт аккультурации в условиях другой культуры, позволяют утверждать, что подготовка специалистов к реальному взаимодействию разных культур носит опосредованный характер, что является основной особенностью обучения межкультурной коммуникации при несовершенном владении иностранным языком студентами экономических специальностей» [7, с. 192].

«Высокая значимость владения иностранным языком требует непрерывных поисков дополнительных резервов для повышения эффективности изучения иностранного языка в языковом вузе. Одним из них является самообучение иностранному языку, составляющее основу самообразовательной деятельности студентов и имеющее некоторые специфические закономерности у обучающихся данной целевой группы» [8, с. 43].

Одними их основных возможностей для осуществления формирующего воздействия на личность и деятельность обучающихся являются стимулирование их личностных сил и обучение их способам самостоятельного познания. Так, педагогическое стимулирование самостоятельной деятельности можно рассматривать как «целенаправленный процесс формирования у обучающегося позиции субъекта познавательной деятельности на основе отбора преподавателем комплекса педагогических стимулов, которые обращены к мотивационной сфере личности обучающегося и побуждают процессы самостимулирования». И в таком случае педагогические стимулы выступают как «целенаправленные воздействия педагога на различные стороны мотивационно-потребностной сферы личности с целью формирования у обучающегося установок на определенное поведение и деятельность» [9, с. 93]. Это означает, что обучающийся должен быть внутренне готов к восприятию стимулов и открыт для внешних побуждений, а значит быть заинтересованным в выполняемой им деятельности. Ведь если обучение стимулирует формирование доминирующего активного познавательного интереса и направлено на овладение обучающимся умениями самоорганизации познавательных действий, то это в результате проявляется в повышении внутренней мотивации самостоятельной познавательной деятельности и уровня самообучаемости [9, с. 62, 92].

Таким образом, для организации успешного самообучения целеполагание должно осуществляться самим субъектом образования, и если рассматривать самообучение как готовность личности выходить за пределы заданного, то можно выделить несколько критериев его формирования:

- наличие мотивации с доминирующим активным познавательным интересом, а значит учет интересов и потребностей обучающегося;

- способность и возможность обучающегося самостоятельно организовать и осуществить задуманное, т.е. посильные цели и задачи, самостоятельно заданные временные рамки и условия деятельности;

- должна быть обеспечена автономность работы, что позволит обучающемуся раскрыть все свои качества, реализовать творческий потенциал и двигаться по собственному «маршруту» .

Самообучение иностранному языку неразрывно связано с самообразовательной деятельностью обучающегося и составляет ее неотъемлемую часть, а результатом этой деятельности становится развитие у студента потребности в самообразовании как особого психологического свойства [8, с. 44]. Развитие личности и ее (само)образование происходит через осознание и оценку собственных действий и деятельности, ее условий и результатов, самоанализ и саморефлексию, а следовательно, через понимание и развитие ключевых компетенций и универсальных учебных действий, которые позволяют обучающемуся планировать, выстраивать и оценивать свою самостоятельную деятельность. При изучении иностранного языка важно задействовать интересы студентов, выявить сферы, которые волнуют их,

\section{Baikal Research Journal}


что усилит мотивацию к обучению и станет стимулом к информальному образованию (по рекомендации преподавателя студенты могут посещать различные иностранные сообщества, общаться с носителями языка, смотреть фильмы и читать литературу на иностранном языке) [10, с. 162].

Одна из проблем, с которой могут столкнуться преподаватели, создающие условия для информального обучения иностранному языку - это мотивирование обучающихся к активному использованию ежедневных возможностей для изучения языка. Если рассматривать самообучение иностранному языку как деятельность, то важно помнить о том, что «мотив любой деятельности соотносится с целью этой деятельности (А.Н. Леонтьев 1983, 2005; А.А. Леонтьев 2003)» [11, c. 110]. Организуя самостоятельную деятельность студентов, необходимо также учитывать важнейшие условия формирования активного познавательного интеpeca, к которым относятся «личная значимость для обучающихся приобретаемых ими знаний, реальная возможность самостоятельно думать и действовать, владение совокупностью навыков и умений, позволяющих самостоятельно «двигаться» в изучаемом материале» [9, с. 102-103].

Среди разнообразных видов мотивов принято выделять внешние и внутренние мотивы. Мотив является внутренним, если он совпадает с целью деятельности. Такие мотивы связаны с познавательной потребностью субъекта, удовольствием и удовлетворением, получаемым от процесса познания. Доминирование внутренней мотивации характеризуется проявлением собственной активности обучающегося в процессе учебной деятельности. И, таким образом, система внутренней мотивации выступает как система самодеятельности и внутреннего контроля, поиска напряжения и трудностей, сопровождаемых интересом и воодушевлением. Внешняя мотивация же возникает в том случае, когда овладение содержанием учебного предмета служит не целью, а средством достижения других целей (получение хорошей оценки, похвалы, признания, подчинение требованиям преподавателя и пр.). И это очевидно, что учебная деятельность полимотивирована, так как процесс обучения совершается для обучающегося не в личностном вакууме, а в сложном взаимопереплетении социально обусловленных процессов и условий [12]. Поэтому также становится очевидной одна из главных задач педагога развитие внутренней осознанной мотивации обучающихся к выполняемой ими деятельности и получаемым знаниям, что позволит им самим добиваться более высоких результатов и их познания будут более глубокими и основательными. Однако переход от внешней к внутренней мотивации зависит не только от действий педагога, но и от внутриличностной готовности самого обучающегося и ситуации учения. И потому, формирование осознанной внутренней мотивации должно происходить постепенно, с первых дней обучения в вузе, поскольку это позволит самому студенту осознать изменения, происходящие в его желаниях и мотивах к изучению языка и выполнению заданий, а также будет способствовать более прочному переходу от одного вида мотивации к другому.

Определяя преобладающие виды мотивации обучающихся к самостоятельному изучению ИЯ в условиях информального образования, можно выделить:

- неустойчивую мотивацию (отсутствие осознанного стремления использовать ИЯ в повседневной жизни);

- неустойчивую внешнюю мотивацию (использование ИЯ в повседневной жизни зависит от рекомендаций преподавателя);

- устойчивую мотивацию (внешняя и внутренняя мотивация к сознательному использованию ИЯ в повседневной жизни);

- выраженную внешнюю и внутреннюю мотивацию (подкрепленная осознанием и описанием конкретных учебных действий, целей и результатов обучения,

\section{Baikal Research Journal}

электронный научный журнал Байкальского государственного университета 
опыта использования ИЯ в повседневной и учебной деятельности, самостоятельностью в планировании и организации своего самообучения и самостоятельной работы) [11, с. 126].

В ходе эмпирических исследований, проводимых среди студентов факультета иностранных языков РГУ им. Есенина и магистрантов института управления и финансов Байкальского государственного университета, касающихся мотивированности обучающихся к процессу самообучения в условиях информального образования и использованию различных приемов и источников самообучения, все отчетливее проявляется то, что преобладающими видами мотивации являются устойчивая мотивация у одной половины опрошенных и неустойчивая внешняя мотивация у другой половины опрошенных студентов. Такие «неустойчивые» результаты обусловлены позицией некоторых студентов «учить и выполнять задания, чтобы получить зачет / сдать экзамен», без внутренней искренней заинтересованности в изучаемом языке, без анализа его влияния на знания и образ жизни обучающегося, и без самоконтроля и рефлексии своей учебной и самостоятельной деятельности. Также получает отражение другая немаловажная проблема - недостаточное нацеливание обучающихся на самостоятельное изучения и практику языка, требующая усиления акцента на применении таких форм работы со студентами в процессе формального обучения на занятиях, которые повлекут за собой возникновение у обучающихся мотивов к дальнейшему самообучению ИЯ в повседневной жизни, желания выстраивать свою самостоятельную работу и осуществлять самоконтроль и рефлексию ее результатов. Наличие рефлексии делает процесс обучения личностно-значимым и позволяет обучающимся внести свое осмысленное представление о собственном учении в процесс контроля и оценки деятельности.

Мотивы к самообучению ИЯ в повседневной жизни можно и нужно формировать на учебных занятиях, так как именно в этот момент преподаватель может воздействовать на личность студента, заинтересовать его, показать пример и направить его деятельность в нужное русло.

Формирование как внутренней, так и внешней мотивации может происходить:

- через применение приемов активного целеполагания, планирования, рефлексии на занятии;

- через обращение к творческой активности, познавательным потребностям обучающихся;

- через включение универсальных учебных действий в задания конспектов занятий;

- через обучение продуктивному использованию различных повседневных источников информального образования языку и актуализацию важности их использования для образования в целом, в том числе и для формальной программы подготовки студентов бакалавриата.

Так, внутренним стимулом становится наличие активного интереса, установок к дальнейшей работе с языком для достижения целей и задач, поставленных самим студентом. Внешним стимулом может выступать необходимость ежедневного самостоятельного выполнения тех или иных действий, использования различных источников для последующего формального контроля результатов и достижений или для выполнения определенных учебных заданий, в том числе групповых, где будут важна и отчетливо видна работа каждого обучающегося.

Формальное образование подразумевает наличие контроля за деятельностью обучающихся. Различные формы контроля могут носить как открытый, так и скрытый характер. Скрытое или открытое проявление контроля в учебном процессе зависит от установки, которую получают учащиеся: на контроль или на речевую практику. Открытый контроль опирается на произвольную форму вни-

\section{Baikal Research Journal}


мания, когда учащиеся отдают себе отчет в контролируемом характере выполняемой ими деятельности, в то время как скрытый контроль проводится на основе непроизвольного внимания, так как деятельность учащегося направлена не на контроль, а на учение.

По аналогии с названными выше формами контроля и видами мотивации, о которых говорилось ранее, можно выделить 3 вида нацеливания обучающихся на самообучение в условиях информального образования в процессе формального обучения: открытое, косвенное и скрытое нацеливание.

Открытое, явное нацеливание происходит через такую формулировку учебных заданий и постановку их целей, что обучающиеся сами видят необходимость в самостоятельной работе и поиске дополнительной информации в информальных источниках и обращаются к ним для выполнения заданий. Такой тип заданий не является чисто информальным образованием, однако, использование подобных заданий в учебном процессе учит студентов обращать внимание на неизвестное, стимулирует их мотивацию к дальнейшему познанию и деятельности, показывает различные источники получения знаний и учит грамотно работать с ними.

Косвенное нацеливание является промежуточным видом и основывается как на открытых, так и скрытых мотивах деятельности. Такое нацеливание может происходить, например, благодаря проблемной ситуации или заданию, сформулированному в форме вопроса, на который обучающийся должен найти ответ. В процессе поиска решения поставленной задачи или вопроса, студенту необходимо будет обратиться не только к уже имеющимся знаниям, но и к дополнительной информации и источникам, что спровоцирует его информальное образование и послужит мотивом для дальнейшей самостоятельной работы и поиска новых источников для пополнения, расширения своих знаний и кругозора.

Третий выделенный вид, скрытое нацеливание, происходит благодаря ориентации обучающихся не на форму работы, а на конечный результат, на сам процесс подготовки ответа на это задание. Так, например, предложение привести примеры англоязычных фильмов или сериалов, или книг на изучаемую тематику и проблему затрагивает личностные интересы обучающихся, является интересным для них, что позволяет им вспомнить и освежить в памяти ранее просмотренные фильмы или прочитанные книги, а тем, кто не готов сразу справиться с этим заданием, дает мотив использовать ресурсы информального образования. В результате мы видим, что кроме выполнения самого задания, студенты одновременно работают и над другими навыками (например, аудирование, чтение с разной степенью понимания, изучение новой лексики), а также открывают для себя привычные ресурсы как источники образования, которые позволяют им работать с иностранным языком фактически в любое время.

Выделенные виды нацеливания представляют большую значимость для всех этапов обучения, поскольку использование подобных заданий в процессе учебных занятий:

- способствует активизации самостоятельной работы студентов, делая их активными осознанными участниками образовательного процесса, что является одной из целей образования;

- дает возможность для формирования у студентов УУД и приемов работы, научного взгляда и стремления к поиску возможностей для саморазвития и самообразования.

Для подтверждения вышесказанного в статье представлена типология заданий указанных форм (табл.), которые могут использоваться в планах-конспектах на занятиях по английскому языку на тему «Travelling», и дан комментарий по каждому из заданий.

\section{Baikal Research Journal}

электронный научный журнал Байкальского государственного университета 
Типология форл заданий, предлагаемых студентал на занятиях по теле "Travelling" и нацеливающих их наинфорлальное образование

\begin{tabular}{|c|c|c|}
\hline Открытое нацеливание & Косвенное нацеливание & Скрытое нацеливание \\
\hline 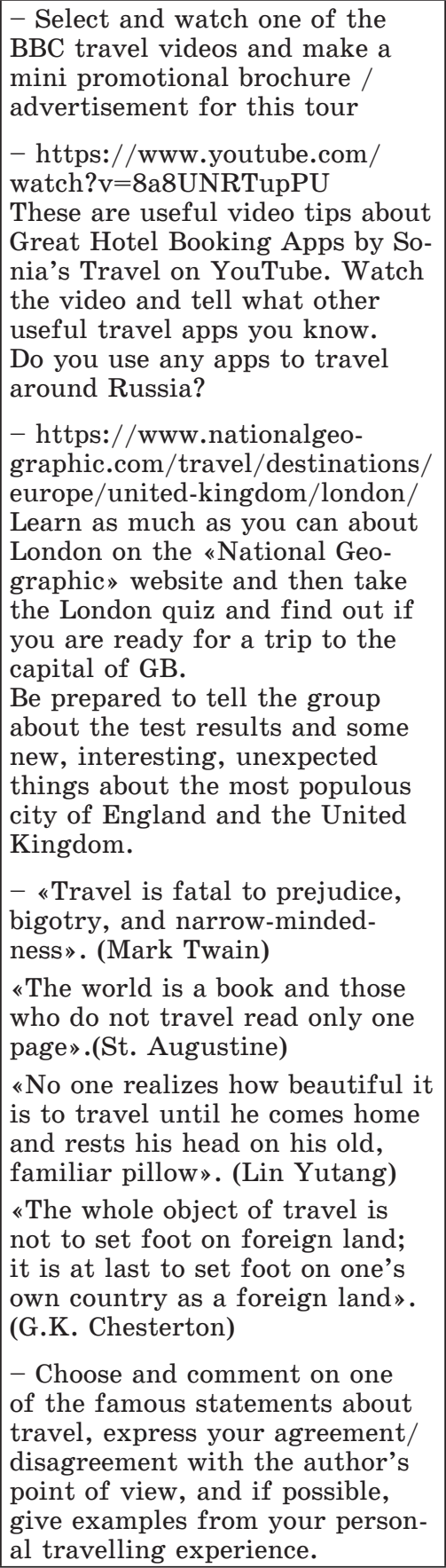 & $\begin{array}{l}\text { - Prepare an article on the } \\
\text { selected topic, edit it (translate } \\
\text { potentially new words, ask fu- } \\
\text { ture readers } 5 \text { questions at the } \\
\text { end of the text), then put the } \\
\text { article on the website / blog. } \\
\text { Read the works of your group- } \\
\text { mates and participate in the } \\
\text { discussions (you can answer } \\
\text { the other writers' questions or } \\
\text { leave a comment on the content } \\
\text { of the article) } \\
\text { - Give examples of songs in } \\
\text { a foreign language on the } \\
\text { topic «Travelling», define the } \\
\text { attitude of the singer to the } \\
\text { journey. What is thetopic vo- } \\
\text { cabulary / new vocabulary used } \\
\text { in the song?Make a short song } \\
\text { glossary. } \\
\text { - @brendanvanson Brendan } \\
\text { van Son, a writer and a pho- } \\
\text { tographer. } \\
\text { In } 2008 \text { he took a degree in } \\
\text { geography and decided that } \\
\text { working in the office is not } \\
\text { for him. During the years of } \\
\text { travelling he visited more than } \\
\text { 80 countries. Collaborates } \\
\text { with the BBC, the National } \\
\text { Geographic Traveler and the } \\
\text { Guardian. } \\
\text { @fosterhunting } \\
\text { Foster Huntington, a photog- } \\
\text { rapher. } \\
\text { In } 2011 \text {, he quit his job at } \\
\text { Ralph Lauren and bought a } \\
\text { motorhome. He even made a } \\
\text { book called "Home is where } \\
\text { you park it" from his travel } \\
\text { photo reports in North Ameri- } \\
\text { ca.That's the spirit of a travel- } \\
\text { er! But what actually can make } \\
\text { a person to give up everything } \\
\text { and start traveling? Is it some } \\
\text { kind of inner propensity, a } \\
\text { trait of character? } \\
\text { Who is he, a person who is } \\
\text { ready to become a «traveler } \\
\text { without a particular home»? }\end{array}$ & $\begin{array}{l}\text { - Give examples of movies } \\
\text { in a foreign language that } \\
\text { show a story of the char- } \\
\text { acters travelling and tell } \\
\text { your groupmates about the } \\
\text { nature of these trips. } \\
\text { - What is the latest } \\
\text { travel / discovery news } \\
\text { you have read on foreign } \\
\text { language websites / blogs / } \\
\text { watched videos about? } \\
\text { Make a short monologue } \\
\text { to interest groupmates in } \\
\text { your report. } \\
\text { - Traveling by plane is } \\
\text { always an exciting adven- } \\
\text { ture, isn't it? A moment } \\
\text { of take-off, beautiful- } \\
\text { bird's-eye views, breakfast } \\
\text { meal without any choice or } \\
\text { a snoring neighbor between } \\
\text { you and your friend...Yeah, } \\
\text { such things happen! } \\
\text { Therefore, to make the } \\
\text { flight more comfortable } \\
\text { you need to know some } \\
\text { hacks and tips. Make a list } \\
\text { of } 5 \text { tips for travel by plane } \\
\text { (possible addition: } \\
\text { the following videos can } \\
\text { help you: } \\
\text { https://www.youtube. } \\
\text { com/watch?v=Js6evJ9o- } \\
\text { QZA,https://www.youtube. } \\
\text { com/watch?v=lcYsDMavu- } \\
\text { vo, https://www.youtube. } \\
\text { com/watch?v=JI6NSL0g- } \\
\text { J2Y) }\end{array}$ \\
\hline
\end{tabular}

\section{Baikal Research Journal}


Рассмотрим примеры каждого вида нацеливания поподробнее.

Задания на открытое нацеливание:

1. Select and watch one of the BBC travel videos and make a mini promotional brochure/ advertisement for this tour. Данная формулировка задания позволяет отнести его к открытому виду нацеливания, поскольку студенты отчетливо осознают необходимость обращения к иноязычному сайту ВВС для просмотра видеоролика о каком-либо городе или достопримечательности, но все же они вольны в выборе объекта изучения и в способе создания своего творческого продукта (брошюры / рекламы), что способствует возникновению мотивов для самостоятельной деятельности. Кроме того, просмотр иноязычных видеороликов с целью выбрать самый интересный и информационный и создать свой собственный креативный рекламный проспект стимулируют познавательную активность студентов, работу с языковым материалом, личную заинтересованность. Студент планирует свою подготовку к заданию: просматривает видеоролики, отбирает из них понравившийся, изучает и анализирует информацию выбранном месте, отбирая те факты и характеристики, которые он отразит в своем рекламном проспекте. Далее, он приступает к реализации поставленных целей через создание творческого продукта. Самоконтроль на данном этапе может осуществляться путем занесения промежуточных и конечных результатов в рефлексивную карту и / или языковой портфель. Институциональный контроль состоит в презентации получившихся рекламных проспектов / брошюр студентами на занятии и попытке вызвать у одногруппников такую же мотивацию к просмотру данного видеоролика / изучению данного города, которая побудила автора брошюры выбрать именно это место.

2. [https://www.youtube.com/watch? $\mathrm{v}=8 \mathrm{a} 8 \mathrm{UNRTupPU}]$ These are useful video tips about Great Hotel Booking Apps by Sonia's Travel on YouTube. Watch the video and tell what other useful travel apps you know. Do you use any apps to travel around Russia? Данный пример также относится к открытому виду нацеливания, поскольку присутствует четкая установка, что и каким образом должны сделать студенты для выполнения задания, т.е. на форму работы. В видео представлены советы по бронированию номеров во время путешествий, что само по себе является интересной и актуальной информацией и подкрепляется использованием современных технологий и приложений, многие из которых действительно могут показаться студентам полезными. Содержательный аспект самостоятельной работы остается таким же, как и в первом примере, но целью просмотра видео теперь является выражение своего мнения и идей, а также приведение конкретных примеров, в том числе и из собственной жизни, что говорит о личностной значимости поставленных целей и работы. Результатом на уровне институционального контроля будет являться ответ студента на поставленные вопросы и предоставление одногруппникам информации о различных приложениях для путешествий, что несомненно вызовет интерес и, возможно, побудит к дискуссиям о пользе того или иного ресурса.

3. [https://www.nationalgeographic.com/travel/destinations/europe/unitedkingdom/london/] Learn as much as you can about London on the "National Geographic» website and then take the London quiz and find out if you are ready for a trip to the capital of GB. Be prepared to tell the group about the test results and some new, interesting, unexpected things about the most populous city of England and the United Kingdom.Это задание также относится к открытому виду нацеливания из-за конкретной установки для организации деятельности студентов. Мотив формируется благодаря возможности проверить свои знания о Лондоне, пройдя несколько тематических тестов на сайте NationalGeographic, и узнать новые факты о самом популярном для изучения городе Великобритании. В процессе работы над заданием студент также фиксирует результаты и новые интересные факты в своей рефлексивной карте и в подготовленной для от-

\section{Baikal Research Journal}

электронный научный журнал Байкальского государственного университета 
вета речи. А затем, на занятии, студенты обмениваются открытиями и результатами, расширяя тем самым свой кругозор и формируя интерес к дальнейшему изучению других городов и стран на одном из самых популярных иноязычных сайтов.

4. [...] Choose and comment on one of the famous statements about travel, express your agreement / disagreement with the author's point of view, and if possible, give examples from your personal travelling experience. Данный пример также открыто показывает форму выполнения работы и желательный результат, но при этом, оставляя перед студентами выбор точки зрения, которой они будут придерживаться. Выражение собственного опыта путешествий делает задание личностно-значимым. Мотивация к рассуждению на данную тему стимулирует студентов искать способы выражения своих мыслей, названия на иностранном языке тех мест, где они побывали, и отбору основных моментов своего путешествия, которые они включат в содержание речи в поддержку / противовес выбранному высказыванию.

Задания на косвенное нацеливание:

1. Prepare an article on the selected topic, edit it (translate potentially new words, ask future readers 5 questions at the end of the text), then put the article on the website / blog. Read the works of your groupmates and participate in the discussions (you can answer the other writers' questions or leave a comment on the content of the article). Данный пример представляет собой косвенное нацеливание студентов, поскольку, с одной стороны, дается конкретная форма работы и задачи, но, с другой стороны, студенты самостоятельно выбирают тему для своей статьи, а значит, отталкиваются от собственных интересов. При выполнении задания, обучающиеся задействуют различные приемы работы и источники информации. А результатом становится ведение обсуждений на сайте / в блоге по различным тематикам, что не только способствует практике языка, но и расширяет научный кругозор студентов, учит полемике и аргументированию своих идей, выражению мыслей.

2. Give examples of songs in a foreign language on the topic "Travelling», define the attitude of the singer to the journey. What is the topic vocabulary / new vocabulary used in the song? Make a short song glossary. Формулировка задания отчетливо отражает необходимую организацию работы - прослушивание иноязычной песни на определенную тематику и анализ ее текста, составление глоссария. Однако выбор песни остается за студентом, который самостоятельно отбирает наиболее информативную песню на заданную тематику и ведет работу с лирикой музыкального произведения, отбирая лексические единицы и конструкции для персонального глоссария. Это задание может стать одним из компонентов языкового портфеля студента как его разработка / творческая работа, а также получить отражение в рефлексивной карте, которую он представит преподавателю по завершению установленного периода времени.

3. [...] That's the spirit of a traveler! But what actually can make a person to give up everything and start traveling? Is it some kind of inner propensity, a trait of character? Who is he, a person who is ready to become a «traveler without a particular home»? Данное задание сформулировано в форме вопросов, побуждающих обучающегося найти ответ, проанализировав не только представленные краткие биографии знаменитых путешественников, но и свою собственную «натуру путешественника». В процессе работы над заданием студент обращается к своим воспоминаниям, выражает свое мнение, применяя различные универсальные учебные действия (УУД) и приемы самостоятельной работы. Такая форма активности позволяет студентам использовать иностранный язык для выражения своих суждений (личностная значимость), а непривычные для российских жителей истории путешественников замотивируют побольше узнать об их образе жизни и приключениях, обратившись к различным источникам на ИЯ.

\section{Baikal Research Journal}

электронный научный журнал Байкальского государственного университета 
Задания на_скрытое нацеливание:

1. Give examples of movies in a foreign language that show a story of the characters' travelling and tell your groupmates about the nature of these trips. Данный пример относится к скрытому нацеливанию, поскольку студентам не дается никаких конкретных рекомендаций по организации своей самостоятельной работы, а напротив, дается ориентация на конечный результат и самостоятельную подготовку, работу с таким интересным для них источником информального образования, как кинофильмы. Кроме того, студенты сами выбирают фильм и составляют свой рассказ не о кинокартине как таковой, а об изучаемом аспекте культуры, природе путешествий, показанных через призму жизни героев.

2. What is the latest travel / discovery news you have read on foreign language websites / blogs / watched videos about? Make a short monologue to interest groupmates in your report.Это задание также относится к скрытому виду нацеливания, так как для его выполнения студентам придется обратиться к иноязычным ресурсам и ознакомиться с последними популярными новостями из мира путешествий, при этом самостоятельно определяя процедуру работы, подбирая и анализируя источники информации, отбирая необходимые факты и оформляя монолог. Таким образом, студент будет использовать различные УУД и приемы работы, обращаться к информальным источникам и ресурсам, выражать интересные и важные для него факты в конечном продукте своей самостоятельной деятельности.

3. Traveling by plane is always an exciting adventure, isn't it? A moment of takeoff, beautiful bird's-eye views, breakfast meal without any choice or a snoring neighbor between you and your friend... Yeah, such things happen! Therefore, to make the flight more comfortable you need to know some hacks and tips. Make a listo f 5 tips for travel by plane. Данное задание относится к скрытому нацеливанию и обращается к эмоциональной сфере обучающегося и его опыту, если таковой имеется. Тем самым, делая процесс подготовки индивидуализированным, интересным и увлекательным для самого обучающегося, а также информативным для будущих слушателей. Формулировка задания оставляет открытой возможность использования различных иноязычных источников для получения информации на заданную тему, что будет способствовать расширению кругозора обучающихся и их вовлеченности в процесс. Результаты выполнения задания также могут быть занесены в рефлексивную карту или же оформлены в виде проектного задания студента или группы студентов.

Первый опыт включения заданий данной классификации в формальный учебный языковой процесс дает право говорить о том, что «...систематическое включение иностранного языка в повседневную коммуникативную, трудовую, познавательную деятельность, использование дополнительных источников и средств для изучения и совершенствования языка, умение выбирать, классифицировать нужную и полезную информацию, источники и выстраивать свои самостоятельные траектории / цели работы над языком позволяют студентам достигать более высоких результатов в освоении языка» [1].

Приведенная типология заданий является примером тематического нацеливания студентов на самостоятельную работу и поиск дополнительных источников для получения знаний и практики ИЯ. Включение подобных заданий в каждое учебное занятие, как профессиональной, так и лексической, грамматической направленности, наряду с применением других педагогических технологий и отработкой действий и приемов, важных для самостоятельной деятельности, будет способствовать всестороннему развитию студентов, закреплению и совершенствованию имеющихся знаний и навыков, а также более продуктивному и быстрому развитию осознанных мотивационных стимулов и потребности к личностной вовлеченности в образовательный процесс.

\section{Baikal Research Journal}

электронный научный журнал Байкальского государственного университета 


\section{Список использованной литературы}

1. Лискина Т.В. Возможности организации учебного процесса при обучении иностранным языкам в контексте информального вида образования (уровень языкового вуза) [Электронный ресурс] / Т.В. Лискина, Н.С. Паульзен // Baikal Research Journal. — 2017. T. 8, № 4. - DOI: 10.17150/2411-6262.2017.8(4).4. - Режим доступа: http://brj-bguep.ru/ reader/article.aspx $? \mathrm{id}=21892$.

2. Немченко А.В. Информальное образование английскому языку на основе использования театрально-лингвистического метода обучения [Электронный ресурс] / А.В. Немченко. - Режим доступа: http://globalnrav.ast.social/44-nauchnye-stati/ nauchnye-stati/336-informalnoe-obrazovanie-anglijskomu-jazyku-na-osnove-ispolzovanijateatralno-lingvisticheskogo-metoda-obuchenija.html.

3. Завьялова А.Г. Влияние междисциплинарных технологий обучения иностранному языку на формирование профессиональных свойств будущего специалиста / А.Г. Завьялова // Известия Иркутской государственной экономической академии. - 2015. - Т. 25, № 4. - C. 728-734. - DOI: 10.17150/1993-3541.2015.25(4).728-734.

4. Завьялова А.Г. Творческий подход к обучению иностранному языку взрослых в системе дополнительного образования / А.Г. Завьялова // Известия Иркутской государственной экономической академии. - 2014. - № 1 (93). - С. 150-155.

5. Лискина Т.В. Современные подходы к определению понятия «информальное образование» / Т.В. Лискина, Н.С. Паульзен // Известия Байкальского государственного университета. - 2018. - T. 28, № 1. - C. 131-137. - DOI: 10.17150/2500-2759.2018.28(1).131-137.

6. Тамбовкина Т.Ю. Самообучение иностранному языку как основная составляющая языкового самообразования / Т.Ю. Тамбовкина // Иностранные языки в школе. - 2005. — № 5. - С. $76-80$.

7. Завьялова А.Г. О некоторых причинах несовершенного владения иностранным языком студентами неязыкового вуза / А.Г. Завьялова // Известия Иркутской государственной экономической академии. - 2016. — T. 26, № 2. - C. 191-196. — DOI: 10.17150/19933541.2016.26(2).191-196.

8. Тамбовкина Т.Ю. Некоторые закономерности самообучения иностранным языкам студентов-лингвистов / Т.Ю. Тамбовкина // Вестник Балтийского федерального университета им. И. Канта. Серия: Филология, Педагогика, Психология. - 2007. — № 2. C. $42-48$.

9. Еремина Е.И. Влияние самообучения на развитие творческой активности будущего специалиста : дис. ... канд. пед. наук : 13.00.01 / Е.И. Еремина. - Воронеж, 2000. - 172 с.

10. Малышева Е.Б. Стимулирование студентов к информальному образованию в процессе преподавания иностранного языка / Е.Б. Малышева, Л.А. Микаелян, А.В. Окерешко // Проблемы современного педагогического образования. - 2017. - № 54-6. - С. 161-167.

11. Колесников А.А. Концептуальные и технологические основы профориентационного обучения иностранному языку в системе непрерывного филологического образования : дис. ... д-ра пед. наук : 13.00 .02 / А.А. Колесников. - М., 2017. - 167 с.

12. Колесников А.А. Профориентационное обучение иностранным языкам в школе и вузе: от теории к технологии / А.А. Колесников. - Рязань : Изд-во Рязан. гос. ун-та им. С.А. Есенина, 2018. - 400 с.

\section{References}

1. Liskina T.V., Paulsen N.S. Possibilities for Organization of Educational Process in Teaching Foreign Languages in the Context of Informal Education (Linguistic University Level). Baikal Research Journal, 2017, vol. 8, no. 4. - DOI: 10.17150/2411-6262.2017.8(4).4. (In Russian).

2. Nemchenko A.V. Informal Learning English Through the use of Theatrical and Linguistic Training Method. Available at: http://globalnrav.ast.social/44-nauchnye-stati/ nauchnye-stati/336-informalnoe-obrazovanie-anglijskomu-jazyku-na-osnove-ispolzovanija-teatralno-lingvisticheskogo-metoda-obuchenija.html. (In Russian).

3. Zavyalova A.G. The Iinterdisciplinary Technologies Impact of Foreign Language Teaching on the Formation of Future Specialists Professional Skills. Izvestiya Irkutskoy gosudarstvennoy ekonomicheskoy akademii = Izvestiya of Irkutsk State Economics Academy, 2015, vol. 25, no. 4, pp. 728-734. DOI: 10.17150/1993-3541.2015.25(4).728-734. (In Russian).

\section{Baikal Research Journal}


4. Zavyalova A.G. A Creative Approach to Teaching Adults a Foreign Language in the System of Additional Education. Izvestiya Irkutskoy gosudarstvennoy ekonomicheskoy akademii = Izvestiya of Irkutsk State Economics Academy, 2014, no. 1 (93), pp. 150-155. (In Russian).

5. Liskina T.V., Paulsen N.S. Modern Approaches to the Definition of «Informal Education». Izvestiya Baykal'skogo gosudarstvennogo universiteta = Bulletin of Baikal State University, 2018, vol. 28, no. 1, pp. 131-137. DOI: 10.17150/2500-2759.2018.28(1).131-137. (In Russian).

6. Tambovkina T.Yu. Foreign language self-learning as a main constituent of language self-education. Inostrannye yazyki $v$ shkole $=$ Foreign languages at School, 2005, no. 5, pp. 76-80. (In Russian).

7. Zavyalova A.G. On Some Reasons for the Poor Command of the Foreign Language by the Students of Non-Linguistic Universities. Izvestiya Irkutskoy gosudarstvennoy ekonomicheskoy akademii = Bulletin of Irkutsk State Economics Academy, 2016, vol. 26, no. 2, pp. 191-196. DOI: 10.17150/1993-3541.2016.26(2).191-196. (In Russian).

8. Tambovkina T.Yu. Some Special Feature of Self-learning in FLT of Linguistic Students. Vestnik Baltiiskogo federal'nogo universiteta im. I. Kanta. Seriya: Filologiya, Pedagogika, Psikhologiya = Bulletin of Immanuel Kant Baltic Federal University. Series: Philology, Pedagogy, Psychology, 2007, no. 2, pp. 42-48. (In Russian).

9. Eremina E.I. Vliyanie samoobucheniya na razvitie tvorcheskoi aktivnosti budushchego spetsialista. Kand. Diss. [Impact of self-education on developing vreative activity of future specialist. Cand. Diss.]. Voronezh, 2000. 172 p.

10. Malysheva E.B., Mikaelian L.A., Okereshko A.V. Encouraging Students to Informal Education in the Process of Foreign Language Teaching. Problemy sovremennogo pedagogicheskogo obrazovaniya = Problems of Modern Pedagogical Education, 2017, no. 54-6, pp. 161167. (In Russian).

11. Kolesnikov A.A. Kontseptual'nye i tekhnologicheskie osnovy proforientatsionnogo obucheniya inostrannomu yazyku $v$ sisteme nepreryvnogo filologicheskogo obrazovaniya. Dokt. Diss. [Conceptual and technological fundamentals of professionally oriented teaching a foreign language in the system of continuous philological education. Doct. Diss.]. Moscow, 2017, vol. 2. $167 \mathrm{p}$.

12. Kolesnikov A.A. Proforientatsionnoe obuchenie inostrannym yazykam $v$ shkole $i$ vuze: ot teorii $k$ tekhnologii [Vocation-Focused Foreign Languages Teaching in High School and University: from Theory to Technology]. Ryazan State University named for S. Yesenin Publ., 2018. $400 \mathrm{p}$.

\section{Информация об авторах}

Лискина Талара Владилировна - ассистент, кафедра германских языков и методики их преподавания, Институт иностранных языков, Рязанский государственный университет им. С. Есенина, Российская Федерация, г. Рязань, e-mail: listpismo@mail.ru.

Блудов Василий Васильевич - доктор физико-математических наук, професcop, Байкальский государственный университет, Российская Федерация, г. Иркутск, e-mail: Vasily-Bludov@yandex.ru.

Оношко Ольга Юрьевна - кандидат экономических наук, доцент, кафедра финансов и финансовых институтов, Байкальский государственный университет, Российская Федерация, г. Иркутск, e-mail: olga_onoshko@mail.ru.

\section{Authors}

Tamara V. Liskina - Assistant Teacher, Chair of Germanic languages and Methods of their Teaching, Institute of Foreign Languages, S.A. Yesenin Ryazan State University, Ryazan, Russian Federation, e-mail: listpismo@mail.ru.

Vasiliy V. Bludov - Doctor habil. in Physics and Mathematics, Professor, Baikal State University, Irkutsk, Russian Federation, e-mail: Vasily-Bludov@yandex.ru.

Olga Yu. Onoshko - Ph.D. in Economics, Associate Professor, Chair of Finance and Financial Institutions, Baikal State University, Irkutsk, Russian Federation, e mail: olga_onoshko@ mail.ru.

\section{Baikal Research Journal}




\title{
Для цитирования
}

Лискина Т.В. Информальное образование в языковом вузе и типы заданий, нацеливающих студентов на самостоятельную работу в условиях информального образования / Т.В. Лискина, В.В. Блудов, О.Ю. Оношко // Baikal Research Journal. — 2019. — T. 10, № 2. - DOI : 10.17150/2411-6262.2019.10(2).2.

\section{For Citation}

Liskina T.V., Bludov V.V., Onoshko O.Yu. Informal Education in Process of Studying Foreign Languages and Types of Tasks that Aim Students at Working Independently in Terms of Informal Education. Baikal Research Journal, 2019, vol. 10, no. 2. DOI: 10.17150/24116262.2019.10(2).2. (In Russian).

\section{Baikal Research Journal}

\author{
электронный научный журнал Байкальского государственного университета
}

